\title{
Instrução por modelagem de David Hestenes: uma proposta de ciclo de modelagem temático e discussões sobre alfabetização científica
}

\author{
Modeling Instruction of David Hestenes: a proposal of thematic
} modeling cycle and discussion on scientific literacy

\author{
Ednilson Sergio Ramalho de Souza ${ }^{1}$ \\ Edilene Farias Rozal ${ }^{2}$
}

\section{Resumo}

O trabalho pedagógico com modelagem matemática pressupõe investigar situações da realidade. Contudo, modelos mentais formados a partir do contato com o mundo vivencial geralmente são incompatíveis com os modelos conceituais. Assim, David Hestenes sustenta a tese de que um dos maiores desafios do ensino e da aprendizagem em ciências e matemática é coordenar modelos conceituais com modelos mentais, o que o levou à elaboração de uma didática em modelagem matemática: a Instrução por Modelagem. Nosso objetivo é apresentar uma proposta de ciclo de modelagem temático elaborada nos pressupostos hestenesianos e discutir sobre possibilidades para alfabetização científica. A questão principal foi saber como emergem indicadores para alfabetização científica durante o ciclo proposto. Trata-se de uma pesquisa bibliográfica com a finalidade de identificar na literatura disponível as contribuições sobre o assunto e levantar possibilidade e desafios para o ensino brasileiro de ciências e matemática. Resultados preliminares indicam que o ciclo de modelagem proposto pode desenvolver indicadores para alfabetização científica de diferentes naturezas.

Palavras-chave: Instrução por Modelagem; Ciclo de Modelagem Temático; Alfabetização Científica; Ensino de Ciências e Matemática.

\section{Abstract}

The pedagogical work with mathematical modeling assumes investigate situations of reality. However, mental models formed from the contact with the experiential world are generally incompatible with the conceptual models. So David Hestenes supports the view that one of the biggest challenges of teaching and learning in science and mathematics is to coordinate conceptual models with mental models, which led to the elaboration of a didactic in mathematical modeling: Modeling Instruction. Our goal is to present a proposal for thematic modeling cycle drawn up in hestenesianos assumptions and discuss possibilities for scientific literacy. The main question was to know how to emerge indicators for scientific literacy for the proposed cycle. This is a bibliographic research in order to identify the available literature contributions on the subject and raise the possibility and challenges for the brazilian teaching science and mathematics. Preliminary results indicate that the proposed modeling cycle can develop indicators for scientific literacy of different natures.

Keywords: Instruction Modeling; Thematic Modeling Cycle; Scientific Literacy; Science and Mathematics Teaching.

\footnotetext{
${ }^{1}$ Universidade Federal do Oeste do Pará | ednilson.souza@ufopa.edu.br

2 Universidade Federal do Pará | lenefarias@ufpa.br
} 


\section{Introdução}

Analogamente a outras disciplinas do currículo escolar, a área de ciências e matemática precisa de metodologias que facilitem a aprendizagem do aluno. Para contribuir com o entendimento dos discentes, julgamos necessário que eles percebam as relações dos conteúdos com situações vivenciadas em seus dia-a-dia. Aprender e ensinar ciências e matemática são processos que deveriam ser pensados e trabalhados em conjunto e serem constitutivos dos saberes associados à prática do professor. Assim, novas abordagens pedagógicas deveriam ser, no atual contexto educacional, uma das preocupações dos professores.

A modelagem matemática, enquanto uma alternativa educacional em ciências e matemática, pressupõe a investigação de situações com referência na realidade dos alunos. No entanto, pesquisas tem revelado que os modelos mentais formados na interação com o mundo vivencial normalmente são incompatíveis com os modelos conceituais (HESTENES, WELLS \& SWACKHAMER, 1992), por isso geram divergências entre o conhecimento científico e o que o estudante imagina. Um exemplo clássico disso é quando o estudante pensa que só existe movimento se houver uma força atuando em um objeto, ou pensa em uma célula como algo plano em vez de tridimensional, ou pensa em átomo como uma esfera sólida, ou diz que a sala de aula tem formato de quadrado em vez de paralelepípedo ou cubo. Desse modo, David Hestenes (2016) argumenta que um dos maiores desafios para ensinar e aprender ciências e matemática é coordenar modelos conceituais com modelos mentais. Suas investigações o levaram à elaboração de uma didática em modelagem matemática chamada de Instrução por Modelagem (AMTA, 2016).

Com a preocupação voltada para o ensino de ciências e matemática, realizamos uma pesquisa Bibliográfica (MALHEIROS, 2011) para identificar contribuição da Instrução por Modelagem e levantar potencialidades e desafios para o desenvolvimento de alfabetização científica. Assim, o objetivo deste artigo é apresentar uma proposta de ciclo de modelagem temático elaborada nos pressupostos hestenesianos e fazer discussões sobre alfabetização científica. Para isso, a questão principal foi saber como emergem indicadores para alfabetização científica durante os estágios do ciclo proposto.

Na primeira seção, nosso objetivo é apresentar ideias gerais sobre a Instrução por Modelagem, destacando a relação estudante x professor x conteúdo. Na segunda seção, nossa atenção estará voltada para o entendimento sobre um ciclo de modelagem, especialmente em termos procedimentais. Na terceira seção, apresentaremos noções gerais sobre alfabetização científica e algumas habilidades necessárias ao seu desenvolvimento. Em seguida, na quarta seção, analisaremos como essas habilidades emergem em um ciclo de modelagem temático. Nossas considerações finais são balizadas na quinta e última seção.

\section{Instrução por Modelagem}

A Instrução por Modelagem (Modeling Instruction) é uma didática em modelagem matemática que surgiu de um programa de pesquisa desenvolvido entre os anos de 1989 a 2005 pelo físico-educador David Hestenes com o apoio da National Science Foundation (NSF). O sucesso da didática foi tão grande que, hoje em dia, a American Modeling 
Teachers Association promove Workshops de Modelagem para professores de ciências e matemática do mundo todo (AMTA, 2016).

O foco da Instrução por Modelagem é favorecer que os estudantes possam coordenar seus modelos mentais com modelos conceituais durante a construção, análise, validação e aplicação de modelos matemáticos. Para isso, os discentes atuam em grupos colaborativos e são orientados a justificar pensamentos e ações em meio a argumentações científicas. 0 professor atua como instrutor no sentido de orientar as pesquisas, apresentar procedimentos e ferramentas de modelagem, gerir o discurso dos discentes durante ciclos de modelagem matemática. Nos ciclos de modelagem, o discurso dos estudantes é apoiado no uso de pequenos quadros-brancos (portable whiteboards) que possibilitam a elaboração de múltiplos registros semióticos (pictóricos, diagramático, gráficos, algébricos) de maneira recursiva. Assim, em cada ciclo, o conteúdo curricular é organizado ao redor de um modelo geral e não em blocos de assuntos pré-determinados. Isso garante maior coerência entre os saberes, evitando a fragmentação do conhecimento em prol da interdisciplinaridade.

Em contribuição, Jackson, Dukerich e Hestenes (2008) comentam que o nome Instrução por Modelagem expressa a ênfase na construção e na aplicação de modelos matemáticos de fenômenos físicos como aspecto central da aprendizagem e do fazer ciências. Os estudantes são engajados no discurso e no debate compartilhado de conteúdos e de técnicas científicas. Sua essência é corrigir muitas fraquezas do método tradicional, inclusive a fragmentação do conhecimento, a passividade dos estudantes e a persistência de crenças ingênuas sobre o mundo físico. O professor procura desenvolver habilidades nos discentes para que deem significado a experiências físicas, compreendam afirmações científicas, articulem coerentemente suas próprias opiniões e as defendam com argumentos convincentes, além de avaliar evidências para apoiar e justificar suas crenças. As orientações são norteadas por uma agenda pedagógica bem definida. Os conteúdos são organizados sobre modelos matemáticos como unidades coerentes da estrutura do conhecimento em vez de blocos de conteúdo.

Brewe (2008) descreve a Instrução por Modelagem em um curso de física universitário norteamericano enfatizando as fases de desenvolvimento, aplicação, adaptação, extensão e revisão de modelos em um esforço para materializar o papel destes em sala de aula. 0 autor comenta que a didática possibilitou a organização efetiva do conhecimento consistente com a prática aceita cientificamente. Comenta ainda que o conteúdo do curso foi organizado em um pequeno número de modelos gerais que puderam ser aplicados em uma ampla classe de situações. Isso resultou em pelo menos dois benefícios: primeiro, a organização curricular levou a uma expertise em modelagem matemática e, segundo, os discentes estudaram um pequeno número de modelos gerais como um corpo de conhecimento coerente.

Para Hestenes (2010), a principal característica da Instrução por Modelagem consiste em ser uma abordagem instrucional investigativa centrada no estudante e orientada pelo professor. Ela focaliza a compreensão de um sistema ou processo físico concreto. O professor guia sutilmente todo o processo investigativo com questões, sugestões e desafios; introduzindo equipamentos, termos padrões, convenções e ferramentas representacionais quando necessário. Os estudantes logo compreendem que o objetivo da investigação é formular e avaliar um modelo matemático do sistema em questão. Assim, o grande jogo é modelar o mundo real, e cada lei teórica subtende um sistema de regras para jogar esse jogo. O objetivo do jogo é construir modelos válidos de objetos e processos reais. Cada 
modelo compreende um conteúdo central do conhecimento científico. Para ele, compreender a ciência é saber como os modelos matemáticos são construídos e validados. Assim, o principal objetivo do ensino de ciências deveria ser aprender o jogo da modelagem matemática. O mecanismo orientador principal é o discurso de modelagem: o que significa que o professor enquadra todo o discurso de sala de aula em termos de modelos e modelagem. O objetivo é sensibilizar os estudantes para a estrutura do conhecimento científico, tanto em aspectos procedimentais quanto declarativos. Para isso, a Instrução por Modelagem é organizada em ciclos de modelagem matemática.

\section{Ciclos de modelagem}

Heidemann, Araújo \& Veit (2012) refletem que o ensino de ciências físicas a partir da técnica dos ciclos de modelagem considera que os aprendizes assimilam o conhecimento significativamente quando inseridos em atividades que os façam comunicar seus modelos aos outros estudantes da classe. Comentam ainda que os ciclos de modelagem têm sido considerados promissores por muitos professores estadunidenses. No entanto, no Brasil essa técnica ainda não é muito conhecida. Nosso objetivo nessa parte do texto é caracterizar um ciclo de modelagem em seus aspectos procedimentais visando a proposição de um ciclo de modelagem temático a ser aplicado em face do contexto educacional brasileiro.

Para objetivos de ensino, argumenta Hestenes (2010), um ciclo de modelagem pode ser decomposto em quatro fases principais: construção, análise, validação e aplicação do modelo. Durante um ciclo de modelagem e dependendo dos objetivos da investigação, pode haver grande variação na ênfase sobre essas quatro fases. Além disso, as mesmas não são necessariamente implementadas em ordem linear, por exemplo, questões levantadas nas fases de análise ou validação podem levar a modificações na fase de construção do modelo.

A fase de construção (ou desenvolvimento) do modelo incorpora algumas ou todas as cinco estruturas universais que caracterizam um modelo matemático, a saber: estrutura sistêmica; estrutura geométrica; estrutura do objeto; estrutura de interação e estrutura temporal (HESTENES, 2010). Os estudantes são apresentados e engajados no uso de ferramentas representacionais para modelar a estrutura de sistemas reais. Isso leva a uma melhora significativa no processo conceitual de construção de modelos. É essencial o reconhecimento que a especificação da estrutura sistêmica é um passo essencial na construção de qualquer modelo. Esse passo consiste em primeiro identificar a composição e interação do sistema a ser modelado e, segundo, a criação de um diagrama do sistema para representar essa informação. Assim, revelar a estrutura do sistema é uma solução prática para a questão de como iniciar um ciclo de modelagem matemática.

A fase de análise do modelo, acrescenta o autor acima, preocupa-se com a extração da informação do modelo, tal como uma explicação física ou uma predição experimental, ou apenas a resposta para a questão sobre os objetos que são modelados. Para modelos lineares simples, essa fase pode ser relativamente trivial, mas além disso pode envolver resolução de equações diferenciais ou sistemas algébricos de muitas variáveis.

A validação do modelo é uma fase que se preocupa com a avaliação da adequabilidade do modelo matemático para caracterizar o sistema/processo sob investigação. Isso pode envolver o planejamento e condução de um experimento para testar algumas predições do modelo, ou pode envolver a avaliação da consistência do 
modelo com resultados teóricos ou fatos experimentais advindos da comunidade científica. Os estudantes aprendem que o resultado dessa fase deve incluir respostas claras para as questões: qual é o seu modelo? e como ele funciona? Os aprendizes modeladores gradualmente aprendem que constituir boas respostas científicas inclui limitações teóricas, estimativas e erros experimentais (HESTENES, 2010).

A fase de aplicação do modelo, assevera Hestenes (2010), consiste na adaptação do modelo desenvolvido em um contexto para caracterizar sistemas ou processos em contextos totalmente diferentes. Isso serve para sensibilizar os estudantes para o fato que modelos incorporam estruturas universais que podem ser adaptadas para modelagem em um número ilimitado de situações.

O ponto culminante de um ciclo de modelagem é o relato e discussão dos resultados em sessões de whiteboarding. Hestenes (2010) reflete que é nesse momento que a aprendizagem dos estudantes ocorre mais profundamente porque tais sessões estimulam a avaliação e consolidação da experiência adquirida na atividade de modelagem. As sessões de whiteboarding tornaram-se uma característica singular da Instrução por Modelagem. Os whiteboards (Figura 01) são pequenos quadros brancos (medindo aproximadamente $80 \mathrm{~cm}$ x 60 cm), são dinâmicos e fáceis de implementar; são efetivos ao permitirem rico suporte nas interações de sala de aula.

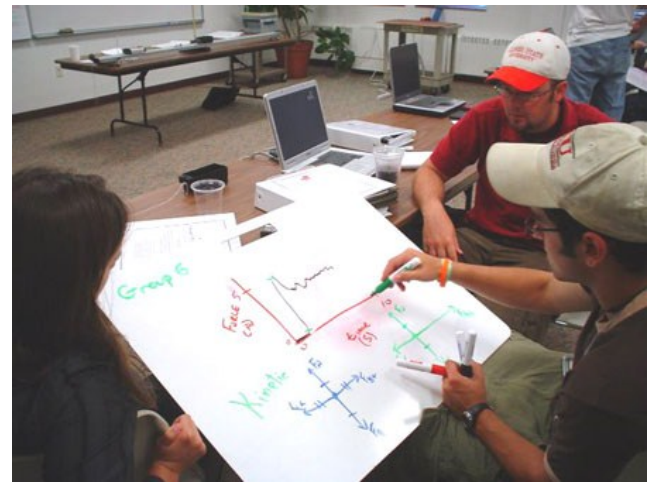

Figura 1. Estudantes norteamericanos durante a produção de um whiteboard (Fonte: http://modelinginstruction.org/professional-development/).

Cada grupo de estudante sumariza seus respectivos modelos matemáticos em whiteboards que são facilmente mostrados para toda a classe. Hestenes (2010) comenta que isso serve como um foco para o relato dos grupos e consequentes discussões. A comparação de whiteboards de diferentes equipes normalmente produz provocações produtivas. O ponto principal é que a discussão em classe é centrada sobre as inscrições simbólicas visíveis que servem como âncoras para compreensão compartilhada.

A partir do que propõe Hestenes (2010) e também Wells, Hestenes \& Swackhamer (1995); Jackson, Dukerich \& Hestenes (2008); Heidemann, Araújo e Veit (2012) sobre o desenvolvimento de ciclos de modelagem, elaboramos uma proposta de ciclo de modelagem temático configurado em quatro estágios gerais, conforme o Quadro 01.

Diferentemente dos ciclos de modelagem realizados pelo grupo de D. Hestenes, cujo início é sempre uma atividade experimental, em nossa proposta, o início de um ciclo de modelagem passa a ser um tema. Nesse ponto concordamos com Heidemann, Araújo \& Veit (2012) quando argumentam que o começo de um ciclo de modelagem pode ser conduzido de diferentes maneiras, podendo-se explorar vídeos, simulações computacionais, experimentos de laboratório, problemas abertos etc. Importa ainda frisar que, enquanto os 
estágios do Quadro 01 são desenvolvidos na ordem em que estão apresentados, as ações principais não obedecem uma ordem fixa para serem realizadas no desenvolvimento de cada estágio. Acreditamos que ciclos temáticos sejam úteis para orientar o planejamento e desenvolvimento de atividades a partir de quaisquer assuntos da realidade brasileira, podendo favorecer à alfabetização científica.

Quadro 1. Um ciclo de modelagem temático.

\begin{tabular}{|c|c|c|}
\hline \multicolumn{2}{|r|}{ Estágios } & Ações principais \\
\hline I & Descrição do Tema & $\begin{array}{l}\text { - Seleção de um tema a ser investigado pelas equipes. } \\
\text { - Análise das estruturas: sistêmica, geométrica, do objeto, de } \\
\text { - } \quad \text { Elaboração e temporaalo de um diagrama de descrição. } \\
\text { - } \quad \text { Levantamento de um conjunto de variáveis (dependentes e } \\
\text { - independentes) e constantes. } \\
\text { - Definição de uma questão de modelagem. }\end{array}$ \\
\hline II & Produção de Dados & 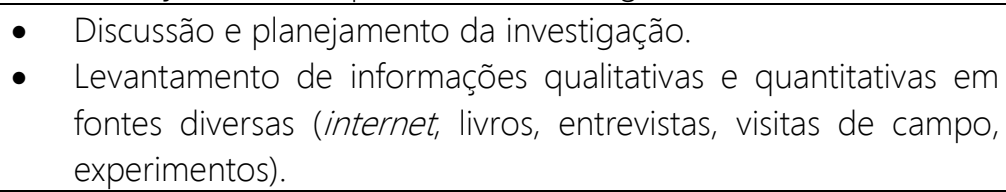 \\
\hline III & $\begin{array}{l}\text { Desenvolvimento do } \\
\text { Modelo }\end{array}$ & $\begin{array}{l}\text { - Construção, análise, validação e aplicação de modelos } \\
\text { matemáticos (múltiplas representações). } \\
\text { - Produção de whiteboards (organização dos modelos } \\
\text { matemáticos). }\end{array}$ \\
\hline IV & $\begin{array}{l}\text { Sessões de } \\
\text { Whiteboarding }\end{array}$ & $\begin{array}{l}\text { - Discussão dos modelos matemáticos (procedimentos e } \\
\text { conceitos). } \\
\text { - Discurso de modelagem (argumentação científica). } \\
\text { - } \begin{array}{l}\text { Aprofundamentos conceituais (problemas abertos, } \\
\text { experimentos, simulações computacionais). }\end{array}\end{array}$ \\
\hline
\end{tabular}

Fonte: elaboração dos autores

\section{Alfabetização científica}

A alfabetização científica, termo traduzido do inglês scientific literacy, tem sido um objetivo para o ensino de ciências da natureza perseguido por diversos países desde a década de 50 do século XX. Ganhou força após o lançamento do satélite Sputnik pela então Rússia em outubro de 1957, chamando a atenção dos Estados Unidos para o fato de que deveriam investir na educação científica e tecnológica dos jovens americanos. Destaca-se que esse fato histórico posteriormente também teve grande repercussão no currículo de ciências brasileiro.

Na literatura nacional e internacional existem diversas definições para alfabetização científica, porém podemos dizer que são equivalentes. No geral, se referem a competências de estudantes, sejam jovens ou adultos, para fazerem uso do conhecimento científico em situações reais; referem-se à capacidade de utilização de provas e dados para avaliar a qualidade das informações e argumentos apresentados pelos cientistas e pelos meios de comunicação de massa; descrevem a capacidade de um indivíduo para compreender as leis científicas, teorias, fenômenos e coisas do mundo natural e tecnológico (DRAGOS e MIH, 2015). 
No Brasil, encontramos autores que usam os termos letramento científico, enculturação científica, literacia científica para se referirem ao objetivo do ensino de ciências naturais que vise a formação cidadã dos estudantes para o domínio e uso dos conhecimentos científicos e tecnológicos nos mais diferentes momentos de suas vidas (SASSERON, 2015). Chassot (2014), um dos maiores defensores da alfabetização científica brasileira, argumenta que a responsabilidade maior no ensinar ciências é fazer com que nossos estudantes se transformem com o ensino que fazemos em homens e mulheres mais críticos, tornando-se agentes de mudanças no mundo em que vivemos. Para este autor, alfabetização científica é um "conjunto de conhecimentos que facilitariam aos homens e mulheres fazer uma leitura do mundo onde vivem" (p. 62). Mas quais saberes seriam esses? Como promover a aquisição desses saberes em aulas de ciências e matemática?

Segundo o Programa Internacional de Avaliação de Estudantes, PISA (2013), compreender e participar no debate crítico sobre as questões que envolvem a ciência e a tecnologia exige o domínio de três competências gerais. A primeira é a capacidade de fornecer explicações a fenômenos naturais, artefatos técnicos e tecnologias e suas implicações para a sociedade. Tal capacidade subtende o conhecimento sobre ideias, estrutura e objetivos da ciência. A segunda é ter compreensão sobre métodos e técnicas da pesquisa científica: identificar questões que podem ser respondidas pela investigação científica; identificar se os procedimentos foram utilizados adequadamente e propor formas para que tais questões possam eventualmente serem abordadas. A terceira competência está relacionada à capacidade de interpretar e avaliar cientificamente dados e provas, bem como avaliar se as conclusões são justificáveis.

Ao dialogar sobre as condições para alfabetização científica pela pesquisa, tal como aponta a segunda competência do PISA (2013), Demo (2010) referindo-se sobre a prática discente, reflete que o aluno deve formar-se construindo conhecimento pela pesquisa. Para isso é necessária a mediação docente para levar até esse aluno os desafios da aprendizagem. Desafios que o faça ser capaz de pesquisar e colaborar com argumentos científicos. $O$ autor reflete ainda que o aluno precisa saber produzir conhecimento próprio, precisa saber pensar. Nesse sentido, a alfabetização científica pode fazer parte do projeto pedagógico da escola. A meta de qualquer escola poderia ser "fazer o aluno autor que, produzindo conhecimento pela pesquisa, também se forme melhor" (p. 118). Neste momento das reflexões começamos a perceber uma diversidade de competências e habilidades necessárias ao desenvolvimento de alfabetização científica.

Mesmo considerando essas várias competências indispensáveis aos alfabetizados cientificamente, é possível estabelecer algumas convergências entre elas. Sasseron (2010) agrupa tais confluências em três blocos, denominados pela autora de Eixos Estruturantes da Alfabetização Científica. O primeiro eixo refere-se à compreensão básica de termos, conhecimentos e conceitos científicos fundamentais. O segundo preocupa-se com a compreensão da natureza das ciências naturais e dos fatores éticos e políticos que circundam sua prática. O terceiro e último eixo compreende o entendimento das relações existentes entre ciência, tecnologia, sociedade e ambiente. Percebe-se que a classificação da autora se harmoniza com as três competências apresentadas mais acima na visão do PISA (2013). No entanto, a autora não se contenta com competências gerais e passa a especificar algumas habilidades específicas para alfabetização científica.

A partir dos eixos estruturantes, a autora propõe Indicadores de Alfabetização Científica capazes de refletir evidências de como a mesma está se desenvolvendo nas atividades 
propostas aos estudantes. Em número de dez, são eles: a seriação, organização e classificação de informações; o levantamento e teste de hipóteses; a justificativa, previsão e a explicação; o raciocínio lógico e proporcional (SASSERON, 2010). Justificativa, previsão e explicação podem ser reunidos em um único indicador: o modelo explicativo (SASSERON, 2010). Como esses indicadores podem emergir nos estágios do ciclo de modelagem temático proposto no Quadro 01?

\section{Possíveis emergências}

Nosso interesse nessa seção é fazer uma análise qualitativa do ciclo de modelagem apresentado no Quadro 01 visando relacionar suas ações principais aos indicadores de alfabetização científica de Sasseron (2010). Isso deverá possibilitar a elaboração de quadro de referência para o desenvolvimento de alfabetização científica com ciclos de modelagem temáticos.

\section{Descrição do tema}

Importante ressaltar que a palavra tema assume conotações diversas em nossa proposta de ciclo de modelagem, pode ser uma situação do cotidiano, uma notícia de jornal, um experimento, uma simulação computacional, um vídeo, um problema aberto, construção de artefatos tradicionais etc. A seleção do tema de modelagem parte do contexto sociocultural dos discentes. A fonte de interesse do tema pode ser uma curiosidade dos alunos, notícia de jornal ou uma situação-problema intrigante para os mesmos. O professor tem papel importante no encaminhamento do tema, pois ele pode fornecer subsídios importantes para a tomada de decisão dos estudantes (BURAK e KLÜBER, 2011). Em complemento, Bassanezi (2015) informa que a escolha de temas pelos próprios estudantes é importante para que os mesmos possam sentir-se corresponsáveis pelo processo de modelagem matemática, tornando suas participações mais efetivas. No entanto, a escolha final dependerá também da orientação do professor, que analisará a exequibilidade de cada tema com relação à obtenção de dados, visitas, fontes para pesquisas etc. Em última análise, a seleção do tema vai depender do objetivo pedagógico do professor e dos interesses dos estudantes.

Hestenes (2010) nos ensina que a eficaz descrição de um tema significa revelar os cinco tipos de estruturas universais de um modelo matemático: a) estrutura sistêmica, ou seja, sua composição, ligações entre as partes, ligações com agentes externos; b) estrutura geométrica, quer dizer, sua configuração espacial e localização; c) estrutura do objeto, sendo as propriedades intrínsecas das partes; d) estrutura de interação, isto é, as propriedades das ligações e; e) estrutura temporal, revelando a mudança temporal no estado do sistema. Desse modo, ao final da descrição do tema, o modelador deverá possuir um conjunto de variáveis (dependentes e independentes) e constantes que comporão o futuro modelo matemático.

Por mais que um tema possua subjacente um problema, é necessário deixar esse problema explícito aos estudantes, momento que definimos uma questão de modelagem ou uma situação-problema. D'Amore (2007) argumenta que uma situação-problema deve constituir uma "situação de aprendizagem concebida de maneira tal que os alunos não possam resolver a questão por simples repetição ou aplicação de conhecimentos ou 
competências adquiridas, mas tal que seja necessária a formação de novas hipóteses" ( $p$. 287). Em aditivo, Dante (2011) esclarece que situações-problema são problemas que retratam situações reais do dia a dia do estudante e que exigem o uso da matemática para serem resolvidos. Por meio de conceitos, técnicas e procedimentos procura-se uma organização matemática para dada situação da realidade, organizando os dados em tabelas, traçando gráficos, fazendo operações etc. Normalmente, são problemas que exigem pesquisa e levantamento de dados.

Argumentamos que durante o estágio de Descrição do Tema possam ser desenvolvidos principalmente os indicadores de seriação, classificação e organização de informações, tal como caracterizados por Sasseron (2010):

A seriação de informações é um de nossos indicadores da alfabetização científica. Ela deve surgir quando se almeja o estabelecimento de bases para a ação investigativa. Não prevê, necessariamente, uma ordem que deva ser estabelecida para as informações: pode ser um rol, uma lista de dados trabalhados ou com os quais se vá trabalhar.

A organização de informações ocorre nos momentos em que se discute sobre o modo como um trabalho foi realizado. Esse indicador pode ser vislumbrado quando se explicita a busca por um arranjo de informações novas ou já elencadas anteriormente. Pode surgir tanto no início da proposição de um tema quanto na retomada de uma questão.

A classificação de informações aparece quando se busca estabelecer características para os dados obtidos, o que pode fazer com que essas informações sejam apresentadas conforme uma hierarquia, embora o aparecimento dessa hierarquia não seja condição sine qua non para a classificação de informações. Constitui-se em um indicador voltado para a ordenação dos elementos com os quais se está trabalhando, procurando uma relação entre eles (SASSERON, 2010, p. 19-20) (grifos da autora).

Assim, a seriação de informações poderá surgir na medida em que os estudantes mobilizam informações visando escolher um tema de modelagem. Nesse caso, eles deverão selecionar diferentes tipos de assuntos conforme seus interesses e organizá-los em uma lista de possíveis temas a serem investigados. A classificação de informações poderá surgir conforme os estudantes realizam a descrição do tema, momento em que suas características deverão brotar com maior evidência, possibilitando a categorização das informações conforme graus de semelhanças e diferenças. A seleção, organização e classificações de informações são essenciais na elaboração da questão de modelagem ou situação-problema, momento em que o tema será simplificado visando à produção de dados.

\section{Produção de dados}

Bassanezi (2015) esclarece que a produção de dados consiste em buscar informações relacionadas com o assunto escolhido como tema de modelagem. Essa coleta, qualitativa ou quantitativa, pode ser realizada de diferentes maneiras: por meio de pesquisas ou entrevistas, em que a elaboração de um questionário eficiente e a utilização de alguns conceitos básicos de Estatística são fundamentais; por meio de pesquisa bibliográfica, utilizando dados já obtidos e catalogados em livros e revistas especializadas; por meio de 
experiências planejadas pelos próprios estudantes etc. Quanto à simplificação de dados, o mesmo autor argumenta que os fenômenos são, em geral, excessivamente complexos se considerados em todos os seus detalhes, por isso é necessário restringir e isolar o campo de estudo apropriadamente de tal modo que o problema seja tratável e, ao mesmo tempo, mantenha sua relevância (BASSANEZI, 2004).

Burak e Klüber (2011) refletem que após a definição de uma situação-problema é necessário buscar e coletar dados. Os autores exemplificam essa etapa a partir de uma questão: qual o consumo anual de papel na escola? Tal questão enseja a produção de dados sobre os trabalhos desenvolvidos pela escola relacionados ao consumo de papel: o tipo de atividades realizadas; estimativa da quantidade de papel utilizada (por sala, por ano, por aluno); os tipos de papel; o consumo da administração etc. Tal questão implica fazer um levantamento junto aos professores, alunos, direção, secretaria, busca de informações na internet, visita a fábricas de papel, dentre outros.

Acreditamos que o levantamento e testagem de hipóteses sejam habilidades comumente evocadas no estágio de Produção de Dados, tal como qualificados por Sasseron (2010):

O levantamento de hipóteses aponta instantes em que são alçadas suposições acerca de certo tema. Esse levantamento de hipóteses pode surgir tanto na forma de uma afirmação quanto na de uma pergunta (atitude muito usada entre os cientistas quando se defrontam com um problema).

O teste de hipóteses constitui-se nas etapas em que se colocam à prova as suposições anteriormente levantadas. Pode ocorrer tanto diante da manipulação direta de objetos quanto no nível das ideias, quando o teste é feito por meio de atividades cognitivas com base em conhecimentos anteriores (SASSERON, 2010, p. 20) (grifos da autora).

Apesar de estarmos creditando ao estágio de Produção de Dados a emergência do levantamento e testagem de hipóteses, essas habilidades encontram-se presentes nos outros estágios do ciclo de modelagem.

\section{Desenvolvimento do modelo}

Essa é a fase em que ocorre a construção, análise, validação e aplicação de modelos matemáticos (Hestenes, 2010), bem como a organização desses modelos nos whiteboards. $\mathrm{Na}$ Instrução por Modelagem, um modelo matemático pode ser entendido como um modelo científico descrito em linguagem matemática por meio de múltiplos registros semióticos. Cada grupo decide como fazer essa sistematização dos modelos nos whiteboards usando desenhos, esquemas, tabelas, gráficos, equações etc. Isso faz com que os modelos sejam diferentes entre as equipes, mesmo sendo desenvolvidos a partir da mesma questão de modelagem ou situação-problema.

Biembengut e Hein (2009) refletem que é nessa fase que ocorre a tradução da situação-problema para a linguagem matemática. Os autores refletem ainda que intuição, criatividade e experiência acumulada são elementos indispensáveis para que seja alcançada com êxito.

Nesse estágio, poderão emergir indicadores de alfabetização científica já assinalados acima, sendo necessário: caracterizar as informações (relevantes e não relevantes); 
identificar fatos envolvidos; decidir quais os fatores a serem perseguidos, levantando e testando hipóteses; selecionar variáveis relevantes e constantes envolvidas; selecionar símbolos apropriados para essas variáveis; e descrever essas relações em termos matemáticos. "O objetivo principal deste momento do processo de modelar é chegar a um conjunto de expressões aritméticas ou fórmulas, ou equações algébricas, ou gráfico, ou representações, ou programa computacional, que levem à solução ou permitam a dedução de uma solução" (BIEMBENGUT e HEIN, 2009, p. 14).

O modelo matemático é obtido quando se substitui a linguagem natural das hipóteses por uma linguagem matemática coerente. A resolução de um modelo está sempre atrelada ao grau de complexidade empregado em sua formulação, sendo que muitas vezes é necessário recorrer a métodos computacionais para resolvê-lo (BASSANEZI, 2004).

Nesse momento, contribui Bassanezi (2015), ocorre o processo de aceitação ou rejeição do modelo matemático, geralmente pelo confronto dos dados reais com os valores simulados. "Um bom modelo deve servir para explicar os resultados e tem capacidade de previsão de novos resultados ou relações insuspeitas" (p. 22). Primeiro formula-se um modelo simples que é fundamental para se entender com detalhes o problema e diagnosticar quais características do fenômeno devem ser consideradas mais a sério. No entanto, esse modelo simplista deve ser reformulado pela modificação de variáveis ou nas leis de formação previamente estabelecidas. Contudo, num ambiente escolar, um modelo simples, mesmo que seus dados não correspondam perfeitamente com os da realidade, pode ser bastante eficiente para a aprendizagem.

Isso significa pôr em evidências nos alunos, além das habilidades anteriores, as de justificativa, previsão e explicação:

A justificativa aparece quando, em uma afirmação qualquer, lança-se mão de uma garantia para o que é proposto. Isso faz com que a afirmação ganhe aval, torando-se mais segura.

O indicador da previsão é explicitado ao afirmar uma ação e/ou fenômeno ocorrendo em associação (e como decorrência) a certos acontecimentos

A explicação surge quando se busca relacionar informações e hipóteses já levantadas. Normalmente, à explicação segue-se uma justificativa para o problema, mas é possível encontrar explicações que não possuem essas garantias. Mostram-se, pois, explicações ainda em fase de construção que certamente receberão maior autenticidade ao longo das discussões (SASSERON, 2010, p. 20) (grifos da autora).

Esse estágio do ciclo de modelagem temático enfatiza, a nosso ver, procedimentos ligados mais diretamente à procura do entendimento da situação analisada, ao trabalho com as variáveis envolvidas no fenômeno e a busca por relações capazes de descrever matematicamente as situações para aquele contexto e outros semelhantes. Isso possibilita que os modelos conceituais sejam representados por registro semióticos apropriados, favorecendo a coordenação com os modelos mentais subjacentes.

Nesse sentido, os whiteboards são importantes porque servem de plataforma para a construção recursiva de modelos matemáticos, possibilitando a coordenação de modelos conceituais com modelos mentais. A aquisição de whiteboards talvez seja o maior desafio para desenvolver a Instrução por Modelagem no contexto educacional brasileiro. Isso 
porque eles são fabricados por encomenda e isso gera um investimento em torno de $R \$$ 40,00 por unidade. Sabemos que, infelizmente, nem sempre a Escola ou os professores possuem recursos financeiros para investir na educação de nossos jovens e adultos. Contudo, é possível construir whiteboards de baixo custo financeiro usando papel cartão revestido de papel contact. O papel contact possibilita escrita e correção com marcadores para quadro branco de diferentes cores. A Figura 02 mostra o momento em que estávamos fabricando um whiteboard de baixo custo (esquerda) e um whiteboard produzido por uma equipe (direita) durante um ciclo de modelagem sobre o tema Obesidade.
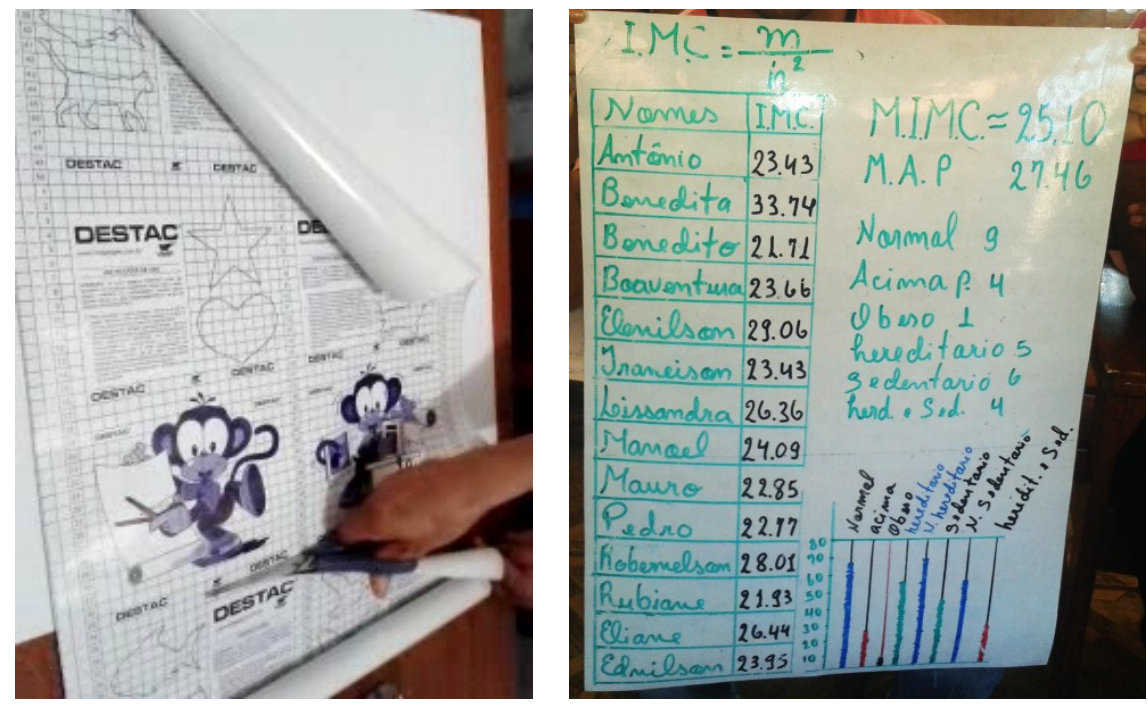

Figura 2. Fabricação dos whiteboards de baixo custo (esquerda) usando papel cartão e papel contact e um whiteboard produzido por uma equipe (direita) (Fonte: Autores).

Ressaltamos que os whiteboards de baixo custo financeiro são uma alternativa quando não se puder encomendar os whiteboards originais. A alternativa que apresentamos acima foi a que nos pareceu mais eficaz e fácil de ser executada. Para fabricar seis whiteboards foi investido somente $R \$ 23,00$, um baixo valor financeiro, mas que resultou em ricos momentos de socialização de conhecimentos pela produção de criativos modelos matemáticos. Além disso, os whiteboards de baixo custo puderam ser facilmente transportados até à escola onde estávamos ministrando um minicurso de modelagem para professores em formação continuada num município do interior do Estado do Pará.

Interessante sublinhar que durante as práticas que temos realizado cada equipe realiza uma análise peculiar sobre seus modelos matemáticos, mas as análises como um todo não são divergentes, sobretudo complementares. De certa forma, essa complementariedade serve para validar os diferentes modelos matemáticos ao reforçar as considerações feitas pelos grupos durante as sessões de whiteboarding.

\section{Sessões de whiteboarding}

Nesse estágio, cada equipe apresenta oralmente os procedimentos realizados, conceitos estudados e resultados alcançados. O professor faz a gestão do discurso de modelagem promovendo a argumentação científica dos estudantes e procurando alcançar o conteúdo curricular por meio da técnica de semeadura (DESBIEN, 2002). Nessa técnica, o professor "planta" em uma equipe uma ideia de discussão sobre um tópico específico e tal equipe fica responsável por disseminar a discussão para toda a classe. Para realizar a 
semeadura é importante que o professor possua uma agenda pedagógica bem definida, pois o currículo da disciplina tende a ser alcançado a partir de várias semeaduras.

Para isso, a classe é organizada em formato de circunferência e cada equipe ocupa uma posição na mesma. O professor também ocupa um lugar na circunferência para poder gerir o discurso de modelagem. Desse modo, pode existir maior interação entre professor \& estudantes e estudantes \& estudantes.

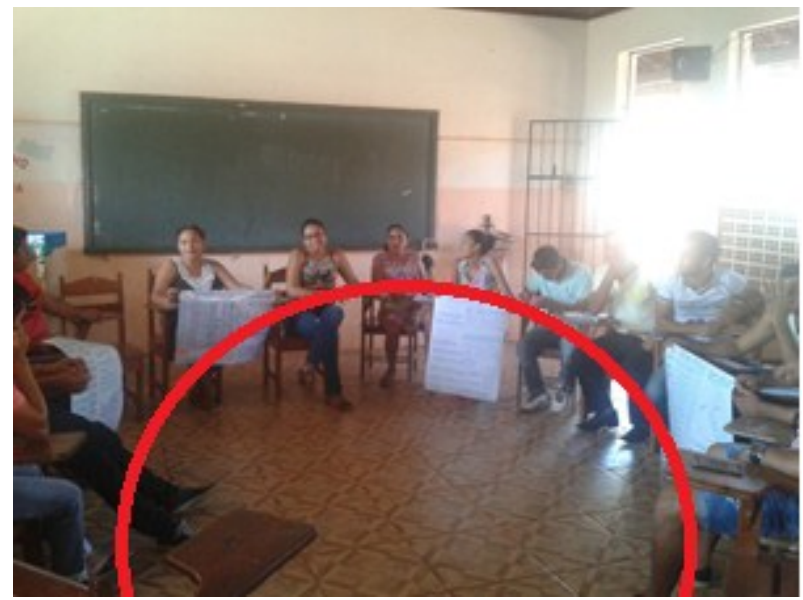

Figura 3. Classe organizada em forma de circunferência durante uma sessão de whiteboarding (Fonte: Autores).

Percebe-se na Figura 03 que a organização da classe em formato de circunferência durante uma sessão de whiteboarding permite que os whiteboards fiquem visíveis simultaneamente para todos os discentes. Isso favorece que os grupos acompanhem o discurso dos outros grupos, podendo fazer suas próprias considerações e argumentações.

Ao comparar os diferentes whiteboards, os grupos levantam questionamentos, fazem hipóteses, apresentam justificativas, formulam explicações, fazem previsões. De acordo com a Teoria da Modelagem (HESTENES, 2006), as discussões geradas com base nos modelos matemáticos registrados nos whiteboards funcionam como suporte para a reformulação de modelos mentais incoerentes dos estudantes, pois possibilitam argumentação científica por meio de análises críticas.

Burak e Klüber (2011) consideram que a análise crítica é um momento destinado a discutir as soluções encontradas. Ocasião em que se fazem as considerações sobre as hipóteses levantadas e testadas. Possibilita 0 aprofundamento de conhecimentos matemáticos ou não matemáticos, tais como os ambientais, sociais, culturais envolvidos no tema. Etapa em que se discute os cuidados com a linguagem e as restrições do modelo. É um momento para mostrar e comentar soluções empíricas e as mais formais. Enfim, "é um momento de interação entre os grupos, de troca de ideias e de reflexões" (p. 13).

Em nossa visão, durante as sessões de whiteboarding pode ocorrer o desenvolvimento de habilidades já mencionadas anteriormente, no entanto, uma habilidade é fundamental nesse estágio: a elaboração de um modelo explicativo. Quanto a essa habilidade, Sasseron (2010) faz o seguinte comentário:

Estes três indicadores - justificativa, explicação e previsão - estão fortemente imbricados entre si, e a completude da análise de um problema se dá quando é possível construir afirmações que mostram relações entre eles, pois, desse modo, têm-se elaborada uma ideia capaz de estabelecer um padrão de comportamento que pode ser estendido a 
outras situações. Além disso, essa ideia, se bem estruturada, deve permitir que se percebam as relações existentes entre os fenômenos do mundo natural e as ações humanas sobre ele. Caso isso ocorra, estaremos diante de outra habilidade importante par o desenvolvimento da alfabetização científica, principalmente para a física: a construção de modelo explicativo capaz de tornar clara a compreensão que se tem de um problema qualquer assim, as relações podem ser construídas entre esse conhecimento e outras esferas da ação humana (p. 21).

Argumentamos que no momento da avaliação da capacidade preditiva e explicativa do modelo matemático, principalmente durante as sessões de whiteboarding, ocorra a emergência do indicador modelo explicativo.

Ressaltamos que, dos dez indicadores para alfabetização científica propostos por Sasseron (2008; 2010), apenas dois não foram contemplados em nossa análise. Isso porque os indicadores para raciocínio lógico e proporcional dificilmente podem ser detectados pela análise procedimental, necessitando de exame mais minucioso nas falas dos estudantes, o que foge do escopo de nossas discussões, as quais levaram em consideração ações procedimentais realizadas durante os estágios do ciclo de modelagem temático proposto no Quadro 01.

\section{Considerações finais}

Quadro 2. Ciclo de modelagem temático e indicadores para alfabetização científica.

\begin{tabular}{|c|c|c|c|}
\hline \multicolumn{2}{|r|}{ Estágios } & Ações principais & Indicadores para \\
\hline I & $\begin{array}{l}\text { Descrição do } \\
\text { Tema }\end{array}$ & $\begin{array}{l}\text { - Seleção de um tema a ser investigado pelas } \\
\text { - } \quad \text { Análise das estruturas: sistêmica, geométrica, } \\
\text { - } \quad \text { do objeto, de interação e temporal. } \\
\text { - } \quad \text { Levantamenta de de um conjunto de variáveis } \\
\text { - } \quad \text { (dependentes e independentes) e constantes. } \\
\text { - Definição de uma questão de modelagem. }\end{array}$ & $\begin{array}{l}\text { Predominantemen } \\
\text { te seleção, } \\
\text { Organização e } \\
\text { Classificação de } \\
\text { Informações. }\end{array}$ \\
\hline II & $\begin{array}{l}\text { Produção de } \\
\text { Dados }\end{array}$ & $\begin{array}{l}\text { - Discussão e planejamento da investigação. } \\
\text { - Levantamento de informações qualitativas e } \\
\text { quantitativas em fontes diversas (internet, } \\
\text { livros, entrevistas, visitas de campo, } \\
\text { experimentos). }\end{array}$ & $\begin{array}{l}\text { Predominantemen } \\
\text { te levantamento e } \\
\text { teste de hipóteses. }\end{array}$ \\
\hline III & $\begin{array}{l}\text { Desenvolvimento } \\
\text { do Modelo }\end{array}$ & $\begin{array}{l}\text { - Construção, análise, validação e aplicação de } \\
\text { modelos matemáticos (múltiplas } \\
\text { representações). } \\
\text { - } \begin{array}{l}\text { Produção de whiteboards (organização dos } \\
\text { modelos matemáticos). }\end{array} \\
\end{array}$ & $\begin{array}{l}\text { Predominantemen } \\
\text { te justificativa, } \\
\text { previsão e } \\
\text { explicação. }\end{array}$ \\
\hline IV & $\begin{array}{l}\text { Sessões de } \\
\text { Whiteboarding }\end{array}$ & $\begin{array}{l}\text { - Discussão dos modelos matemáticos } \\
\text { (procedimentos e conceitos). } \\
\text { - } \quad \text { Discurso de modelagem (argumentação } \\
\text { científica). } \\
\text { - } \quad \text { Aprofundamentos conceituais (problemas } \\
\end{array}$ & $\begin{array}{l}\text { Predominantemen } \\
\text { te modelo } \\
\text { explicativo. }\end{array}$ \\
\hline
\end{tabular}




\begin{tabular}{|l|l|l|l|}
\hline & $\begin{array}{l}\text { abertos, experimentos, simulações } \\
\text { computacionais). }\end{array}$ & \\
\hline
\end{tabular}

Nosso objetivo foi avaliar como podem emergir indicadores para alfabetização científica durante um ciclo de modelagem temático elaborado nos pressupostos da Instrução por Modelagem de David Hestenes. O Quadro 02 resume os principais resultados encontrados.

Grifamos que a organização do Quadro 02 não é definitiva, outros indicadores podem ser incluídos/excluídos no mesmo. No entanto, pensamos que a ideia que norteou sua elaboração pode ser de grande utilidade para o desenvolvimento de ciclos de modelagem temáticos por professores que queiram enfatizar o desenvolvimento de alfabetização científica em seus alunos. Percebe-se que a possibilidade de ocorrer a emergência de indicadores tende a ser crescente conforme se desenvolvem os estágios do ciclo. A descrição do tema seria o momento de "menor" desenvolvimento de alfabetização científica, enfatizando predominantemente os indicadores para seriação, organização e classificação de informações. As sessões de whiteboarding seria o momento de "maior" desenvolvimento, enfatizando, além dos demais indicadores, a habilidade de modelo explicativo.

Ressalta-se que o Quadro 02 foi produto de inferências teóricas a partir de procedimentos típicos desempenhados pelos estudantes durante o ciclo de modelagem temático. Faz-se necessária, portanto, a validação do mesmo em práticas de sala de aula para que possamos aperfeiçoá-lo como um quadro de referência efetivo. Assim, algumas questões surgem como pauta de investigações futuras: Quais indicadores para alfabetização científica emergem a partir da análise das falas dos estudantes em cada estágio do ciclo temático? Como o processo argumentativo pode evidenciar esses indicadores?

Esperamos apenas ter iniciado um debate sobre um tema que ainda é pouco discutido em práticas de Instrução por Modelagem: o desenvolvimento de alfabetização científica. $\mathrm{Na}$ esperança de que outros pesquisadores em ensino de ciências e matemática se interessem pelo assunto, inclusive aprofundando as discussões aqui alinhavadas, daremos prosseguimento em nossas pesquisas a fim de contribuir com futuras discussões que levem à melhoria da educação científica e matemática brasileira, especialmente por meio da modelagem matemática.

\section{Referências}

AMTA. American Modeling Teachers Association. Modeling Workshops for Summer 2016. Disponível em: https://modelinginstruction.org/summer2016-workshops/. Acesso em 07 ago. 2016.

BASSANEZI, R. C. Ensino-aprendizagem com modelagem matemática. São Paulo: Contexto, 2004.

BASSANEZI, R. C. Modelagem matemática: teoria e prática. São Paulo: Contexto, 2015.

BIEMBENGUT. M. S.; HEIN, N. Modelagem matemática no ensino. 5 ed. São Paulo: Contexto, 2009.

BREWE, E. Modeling theory applied: Modeling Instruction in introductory physics. American Journal of Physics, Melville, v. 76, n. 12, p. 1155-1160, Dec. 2008. 
BURAK, D; KLUBER, T. E. Encaminhamentos didático-pedagógicos no contexto de uma atividade de modelagem matemática para a educação básica. In: ALMEIDA, M. W; ARAÚJO, J. L.; BISOGNIN, E. Práticas de modelagem matemática: relatos de experiências e propostas pedagógicas. Londrina: Eduel, 2011. p. 1-27. cap. 2.

CARVALHO, G. S. Literacia científica: conceitos e dimensões. In: AZEVEDO, F.; SARDINHA, M. G. Modelos e práticas em literacia. Lisboa: Lidel, 2009, p.179-194.

CHASSOT, A. Alfabetização científica: questões e desafios para a educação. 6 ed. Ijuí: Unijuí, 2014.

D'AMORE, B. Elementos de didática da matemática. São Paulo: Livraria da Física, 2007.

DANTE, L. R. Formulação e resolução de problemas de matemática: teoria e prática. São Paulo: Ática, 2011.

DEMO, P. Educação e alfabetização científica. São Paulo: Papirus, 2010.

DESBIEN, D. M. Modeling discourse management compared to other classroom management styles in university physic. 2002. 107 f. Dissertation (Doctor of Philosophy) Arizona State University, Arizona, 2002.

DRAGOS, V.; MIH, V. Scientific literacy in school. Procedia - Social and Behavioral Sciences, v. 209, p. $167-172,2015$.

HEIDEMANN, L. A; ARAUJO, I. S.; VEIT, E. A. Ciclos de modelagem: uma proposta para integrar atividades baseadas em simulações computacionais e atividades experimentais no ensino de física. Cad. Bras. Ens. Fís., v. 29, n. Especial 2, 2012, p. 965-1007.

HESTENES, D. Modeling theory and modeling instruction for stem education. 2016. Disponível em: https://secure.hbcse.tifr.res.in/epi6/papers/Review-talks/epiSTEME6_Review Talk_David\%20Hestenes.pdf. Acesso em 07 ago. 2016.

HESTENES, D. Modeling theory for math and science education. In: LESH, R. et al. (Ed.), Modeling student's mathematical modeling competencies (pp. 13-42). New York: Springer, 2010.

HESTENES, D. Notes for a modeling theory of science, cognition and instruction. In: Proceedings Girep Conference. Amsterdam: University of Amsterdam, 2006, p. 34- 65.

HESTENES, D., WELLS, M., e SWACKHAMER, G. Force concept inventory. The Physics Teacher, v. 30, p. 141-158, 1992.

HURD, P. D. Science literacy: Its meaning for american schools. Educational Leadership. October, p. 13-16, 1958.

JACKSON, J.; DUKERICH, L.; HESTENES, D. Modeling instruction: an effective model for science education. Science Educator, v. 17, n. 01, 2008, p. 10-17.

MALHEIROS, B. T. Metodologia da pesquisa em educação. Rio de Janeiro: LTC, 2011.

PISA. Draft science framework. 2013. Disponível em <http://www.oecd.org/pisa/ pisaproducts/Draft\%20PISA\%202015\%20Science\%20Framework\%20.pdf>. Acesso em 07 mar 2015. 
SASSERON, L. H. Alfabetização científica e documentos oficiais brasileiros: um diálogo na estruturação do ensino de física. In: CARVALHO, A. M. P. et al. Ensino de Física. São Paulo: Cengage Learning, 2010. p. 1-27.

SASSERON, L. H. Alfabetização Científica no Ensino Fundamental: estrutura e indicadores deste processo em sala de aula. 2008. 265 f. Tese (Doutorado em Educação) - Faculdade de Educação, Universidade de São Paulo, São Paulo, 2008.

SASSERON, L. H. Alfabetização científica, ensino por investigação e argumentação: relações entre ciências da natureza e escola. Revista Ensaio, Belo Horizonte, v.17, p. 49-67, 2015. Número especial.

WELLS, M.; HESTENES, D.; SWACKHAMER, G. A modeling method for high school physics instruction. 1995. American Journal of Physics. Acesso em 24 de jul., 2016: http://dx.doi.org/10.1119/1.17849. 